\title{
A new anabolic compound, LLP2A-Ale, reserves periodontal bone loss in mice through augmentation of bone formation
}

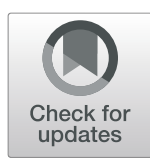

Min Jiang ${ }^{1,2}$, Lixian Liư ${ }^{1,3}$, Ruiwu Liư ${ }^{4}$, Kit S. Lam ${ }^{4}$, Nancy E. Lane ${ }^{1}$ and Wei Yao ${ }^{1 *}$ (D)

\begin{abstract}
Background: Currently, there are no effective medications to reverse periodontal disease (PD)-induced bone loss. The objective of this study was to test a new anabolic compound, LLP2A-Ale, or with the combination treatment of mesenchymal stromal cell (MSC), in the treatment of bone loss secondary to PD.

Methods: PD was induced in mice by placing a ligature around the second right molar. At one week after disease induction, the mice were treated with placebo, LLP2A-Ale, MSCs, or combination of LLP2A-Ale + MSCs, and euthanized at week 4.

Results: We found that PD induced alveolar bone loss that was associated with reduced bone formation. LLP2A-Ale alone or in combination with MSCs sustained alveolar bone formation and reversed alveolar bone loss. Additionally, PD alone caused systemic inflammation and increased the circulating levels of G-CSF, IP-10, MIP-1a, and MIP2, which were suppressed by LLP2A-Ale +/- MSCs. LLP2A-Ale +/- MSCs increased bone formation at the peripheral skeletal site (distal femur), which was otherwise suppressed by PD.

Conclusion: Our findings indicated that LLP2A-Ale treatment rescued alveolar bone loss caused by PD, primarily by increasing bone formation. LLP2A-Ale also attenuated the circulating levels of a series of inflammatory cytokines and reversed the PD-induced suppression of systemic bone formation.
\end{abstract}

\section{Background}

Periodontal disease (PD) is characterized by the progressive destruction of tooth-supporting alveolar bone and is mainly caused by chronic inflammation in response to persistent bacterial insult [1]. Currently, there are no effective medications that reverse PD-induced bone loss and regenerate new bone. There is an unmet medical need for nonsurgical therapeutic options to treat bone loss induced by PD. There are limited drug interventions for PD-induced alveolar bone loss that have been focused on reducing bone resorption. The most commonly available antiresorptive agents are bisphosphonates,

\footnotetext{
* Correspondence: yao@ucdavis.edu

'Department of Internal Medicine, University of California, Davis Medical Center, 4625 2nd Avenue, Sacramento, CA 95817, USA

Full list of author information is available at the end of the article
}

which may be associated with an increased risk for osteonecrosis [2-4]. Other medications include antibiotics, and gluconate mouthwash, which reduce bacteria in the mouth but do not have direct effects on bone. To this end, we have developed a novel compound, LLP2AAle, that has an affinity for both bone (hydroxyapatite tissue) and mesenchymal stromal cells (MSCs). LLP2AAle improves the bone homing of both endogenous and exogenous MSCs [5, 6]. Several studies have been conducted to test this approach in animal models of primary osteoporosis, aging, glucocorticoid-induced bone fragility, and fracture healing $[5,7,8]$. Our data, as well as those from others, have confirmed that MSCs have paracrine effects that reduce inflammation and restore angiogenesis and osteogenesis when they are localized within the bone microenvironment [8-12]. LLP2A-Ale is currently in 
Phase I clinical trial for safety evaluation of this compound in glucocorticoid-induced osteopenia patients, with a further indication of treating osteonecrosis in Phase II. The current study evaluated aimed to evaluate whether LLP2A-Ale, alone or in combination with MSCs, represents a new approach with increased anti-inflammatory activity and bone regeneration, which are essential for the treatment of bone loss and growth of new bone to decrease the risks of tooth loss and dental implants secondary to PD.

\section{Methods}

\section{Animal protocols}

Eight-week-old BALB/C male mice were used in the study (The Jackson Laboratory, Cat\#000651). To induce PD, 6-0 silk ligatures (Fine Science Tools, San Diego, CA, USA) were tied around the right 2nd molars with the knot at the palatal surface of the tooth (Fig. 1a). Control mice did not receive ligatures. Since ligandinduced peak bacterial load and apparent periodontal bone loss that was observed between days 5-7 postligature [13-15], we initiated the interventions on day 8 . All the ligatured mice were randomized into four groups of 8-12 mice each: PD-control (normal saline); PD + LLP2A-Ale $(500 \mu \mathrm{g} / \mathrm{kg}$ weekly by i.p. injection); PD + MSCs (Cell Biologics, Chicago, IL, USA; $1 \times 10^{6}$ i.v. on day 8); and PD + LLP2A-Ale $(1000 \mu \mathrm{g} / \mathrm{kg})+$ MSCs $\left(1 \times 10^{6}\right.$ i.v. on day 8$)$. Ligatures were checked weekly and retied if they became loose. One week and one day before sacrifice, animals were injected with 10 $\mathrm{mg} / \mathrm{kg}$ calcein (Sigma-Aldrich, MO, USA). All mice were euthanized by $\mathrm{CO} 2$ overdose at week 4 . The animal procedures and euthanization protocol were approved by the Institutional Animal Care and Use Committee at UC Davis.

\section{Cytokine multiplex assay}

The levels of cytokines in serum were measured using a 32-plex mouse immunology cytokine/chemokine kit purchased from Millipore Sigma (Burlington, MA, USA) that included eotaxin/CCL11, G-CSF, GM-CSF, IFN- $\gamma$, IL-1 $\alpha$, IL-1 $\beta$, IL-2, IL-3, IL-4, IL-5, IL-6, IL-7, IL-9, IL10, IL-12 (p40), IL-12 (p70), IL-13, IL-15, IL-17, IP-10, KC, LIF, LIX, MCP-1, M-CSF, MIG, MIP- $1 \alpha$, MIP- $1 \beta$, C-X-C motif chemokine ligand 2 (CXCL2, MIP-2), RANTES, TNF- $\alpha$, and VEGF. The samples were run in duplicate using EMD Millipore LMX200 system (Burlington, MA, USA).

\section{MicroCT measurements}

The right maxillae were scanned with a micro-computed tomography system (vivaCT 40; SCANCO Medical, Switzerland) with a resolution of $10.5 \mu \mathrm{m}$ at $75 \mathrm{kVp}$. The sagittal plane of the specimens was set parallel to the $\mathrm{X}$ ray beam axis. Two-dimensional measurements of vertical bone were performed in three central slides that included the three molars in the same grayscale image. The linear distance was measured from the junction of the head and shaft of the implant to the alveolar bone crest $(\mathrm{ABC})$ or vertically from the cement enamel junction $(\mathrm{CEJ})$ to the $\mathrm{ABC}$. Measurements were made in the interdental region between the first and second molars (M1-M2) or the second and third molars (M2-M3). We used the methods reported by Part et al. 2007 to

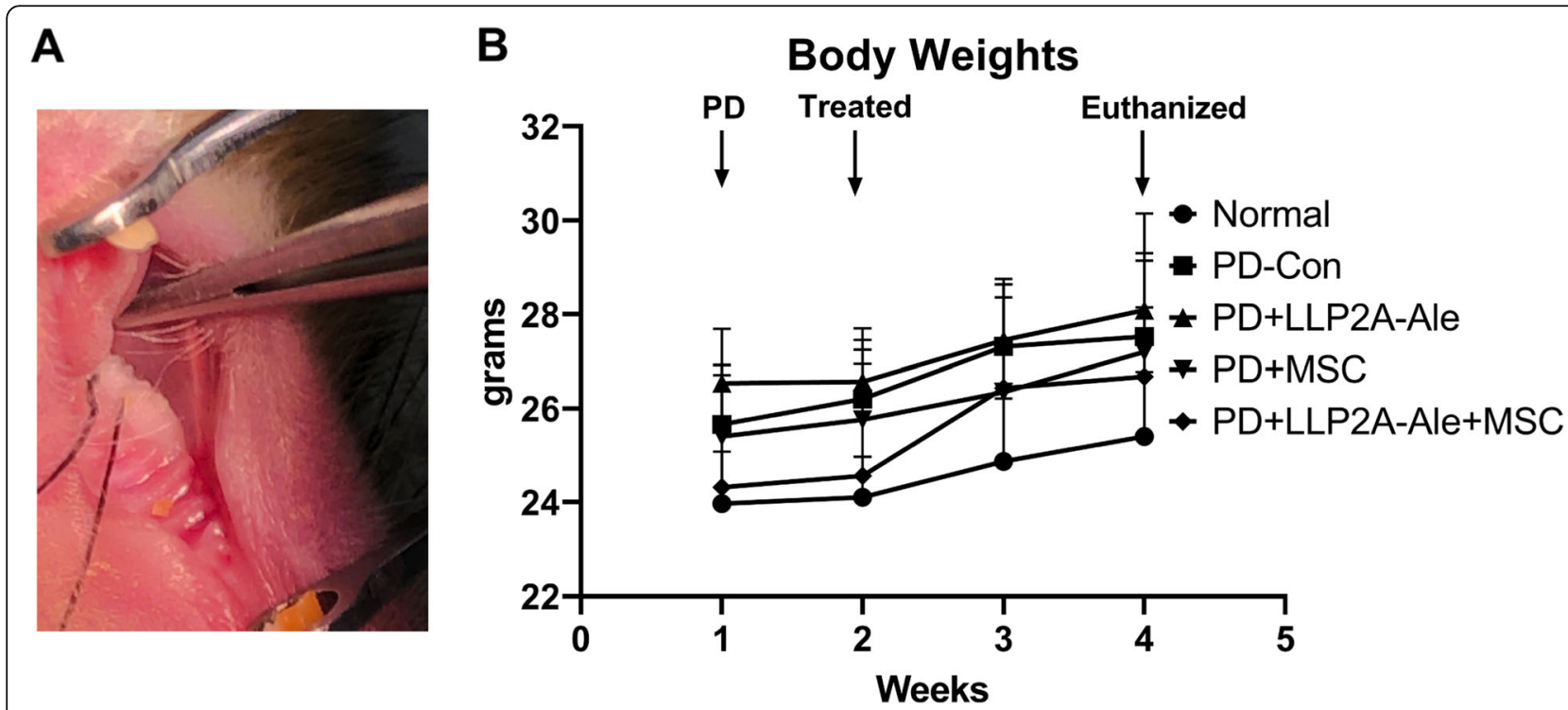

Fig. 1 Periodontitis mouse model and general well-being of the mice during the study. a A ligature was placed around the right second molar of eight-week-old BALB/C mice at week 1. b Treatment started at week 2, and mice were euthanized at week 4 . Bodyweight was recorded weekly during the study period 


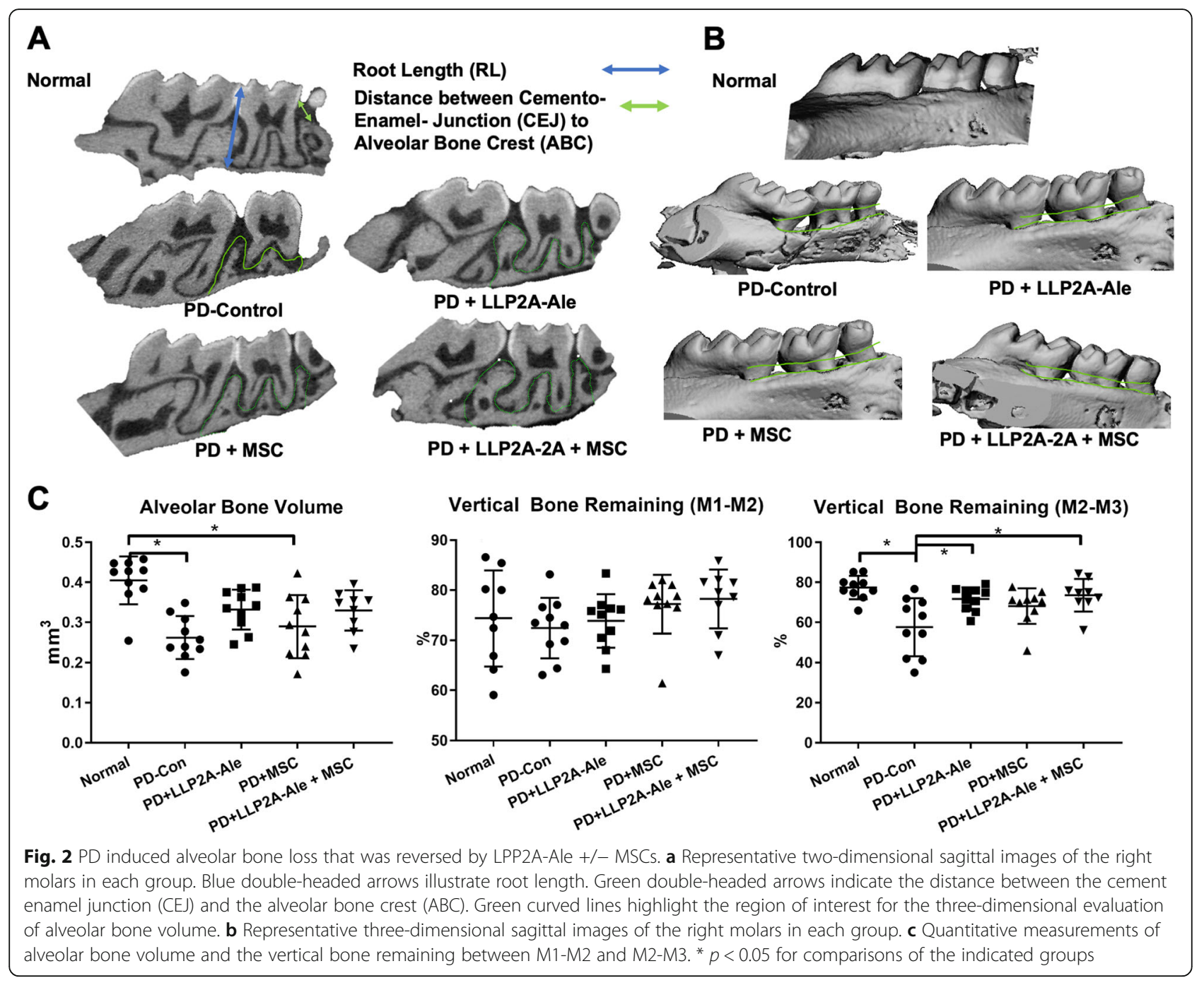

calculate the amount of vertical bone remaining [16] (Fig. 2). To assess volumetric bone mass, alveolar bone parameters of bone volume (BV) and bone volume fraction (BV/TV) were derived from manually contour-drawn regions of interest including the alveolar bone between the 1st and 3rd molars, as highlighted in green in Fig. 2a. MicroCT evaluations were performed by two calibrated examiners (LXL and WY) who were blinded to group assignment.

\section{Histology}

Following sacrifice, the maxillae were collected, fixed for $48 \mathrm{~h}$ in $4 \%$ paraformaldehyde and stored in $-80^{\circ} \mathrm{C}$ until being dehydrated in $30 \%$ sucrose and were embedded in optimal cutting temperature (O.C.T.; Tissue-Tek, Thermo Fisher, Waltham, MA, USA) and cut into serial $8-\mu \mathrm{m}$-thick sections. Cryosections were prepared and imaged with a Keyence BZ-X9000 all-in-one Fluorescence Microscope (Itasca, IL, USA) for MSC tracking ( $n=4$ /group). Surface-based bone formation was quantitated using BIOQUANT image analysis software ( $n=4$ /group) (BIOQUANT Image Analysis Corporation, Nashville, TN, USA) [17].

\section{Statistical analysis}

The results are expressed as the mean \pm standard deviation. One-way ANOVA was used to detect significant differences among the groups. When significance was detected, Dunnett's multiple comparisons test was used to assess pairwise comparisons between groups. A value of $p<0.05$ was considered to indicate statistical significance. Data were analyzed using GraphPad Prism 8 software (La Jolla, CA, USA).

\section{Results}

The general well-being of the mice after ligature placement and treatment

A ligature was placed around the right second molar at week 1 in male eight-week-old BALB/C mice (Fig. 1a). Treatment was started at week 2 . All the mice gained an 
average of $5 \%$ body weight during the study period. The body weight leveled off in the PD-control group at week 3 , while the PD + LLP2A-Ale + MSC group showed a significant increase of $12 \%$ body weight at week 4 compared to baseline (Fig. 1b).

\section{Alveolar bone loss following PD and treatment}

The distance from the CEJ to the $\mathrm{AC}$ was measured at the buccal root of the first maxillary molar and the second molar and between the palatal root of the second maxillary molar and the third molar. Three weeks after ligature placement around the 2nd molar, there was a significant increase in the CEJ-AE distance between the 2nd-3rd molars, indicating periodontal bone loss (Fig. 2a). Three-dimensional reconstruction of the right maxilla confirmed the difference in periodontal bone height in the ligature-induced PD group compared to the normal, nonligatured control group and the other treatment groups (Fig. 2b). Volumetrically, ligature placement caused significant alveolar bone loss and reduced the height of the remaining vertical bone (Fig. 2c). PD + MSC monotherapy evoked similar changes as PD alone, while PD + LLP2A$2 \mathrm{~A}$ with or without combined MSC treatment preserved the alveolar bone mass and vertical bone remaining at M2-M3.

\section{$\mathrm{PD}$ reduced bone formation in the maxilla}

Calcein-labeled frozen maxilla sections were assessed to measure bone apposition. Axial frozen sections of the right and left maxillae were obtained to analyze surfacebased bone formation. A cursory evaluation of maxillae suggested a decrease in the total labeled surface in right maxillae (with a ligature) compared to left maxillae (no ligature) in both the PD-alone and PD + MSC groups (Fig. 3a). Quantitatively, the mineral apposition rate (MAR) was decreased by more than $40 \%$ in the PDalone and PD + MSC groups compared to the normal no ligatured group $(p<0.05)$. The MAR was normalized in both the PD + LLP2A-Ale and PD + LLP2A-Ale + MSC groups, in which it increased by 70 and $45 \%$, respectively, compared to the PD-alone group $(p<0.05)$. The surface-based bone formation rate $(\mathrm{BFR} / \mathrm{BS})$ was decreased by more than $50 \%$ in the PD-alone as well as in $\mathrm{PD}+\mathrm{MSC}$ groups compared to the normal nonligatured group $(p<0.05)$. The BFR/BS returned to normal in both the PD + LLP2A-Ale and PD + LLP2A-Ale + MSC groups. LLP2A-Ale increased BFR/BS by $110 \%$ compared to PD alone $(p<0.05)$ (Fig. 3b). Notably, there were many transplanted MSCs (Fig. 3a, white arrowheads) in the PD + LLP2A-Ale + MSC group, but these MSCs were not on the bone surface and did not colocalize with the double-labeled surface.

\section{Systemic inflammation following PD}

To monitor the changes in systemic inflammation following PD, we measured cytokine and chemokine levels in serum after the mice were euthanized. Among the 32 cytokines and chemokines that were measured, most were below the detection limit, except for G-CSF, IP-10, MIP-1 $\alpha$, MIP2, KC, and RANTES. The PD-control group showed significantly increased serum levels of IP10 , and MIP2 ( $p<0.05$ compared to the normal group) and a trend toward higher G-CSF and MIP- $1 \alpha$ ES levels (Fig. 4), which were lower in the LLP2A-Ale and LLP2A-Ale + MSC-treated groups.

\section{Systemic reduction in bone formation following PD}

To assess whether PD is associated with systemic changes in bone turnover, we obtained frontal sections of the right femur metaphysis (DFM) and lumbar vertebral body for measurements of peripheral skeletal bone mass and bone formation. We report the DFM results here. PD decreased trabecular bone area by $31 \%$ compared to the control (no ligature), and the trabecular bone area was increased $70 \%$ by LLP2A-Ale and $97 \%$ by PD + LLP2A + MSC $(p<0.05)$ compared to PD alone (Fig. 5). There was a significant reduction in the doublelabeled surface in the PD and PD + MSC groups, suggesting reduced osteoblast activity (Fig. 5a, green arrows). Quantitatively, the MAR was decreased by nearly $50 \%$ in the PD-alone as well as the PD + MSC groups compared to the normal non-ligatured group. The MAR was rescued to a normal level in both the PD + LLP2A-Ale and PD + LLP2A-Ale + MSC groups, in which it was increased by 55 and $110 \%$, respectively, compared to the PD-alone group $(p<0.05)$. The BFR/BS was decreased by more than $50 \%$ in the PD-alone and PD + MSC groups compared to the normal nonligatured group. The BFR/BS returned to normal in both the PD + LLP2A-Ale and PD + LLP2A-Ale + MSC groups, in which it was increased by 106 and $167 \%$, respectively, compared to the $\mathrm{PD}$-alone group $(p<0.05)$ (Fig. 5b). There were many transplanted MSCs (Fig. 5a, white arrows) in the bone marrow in PD + LLP2A-Ale + MSC-treated mice, and some of the transplanted MSCs turned yellow and were double-positive for red $(\operatorname{tdTo}$ mato) and green (calcein) (Fig. 5a, yellow arrow), suggesting active mineral apposition in these transplanted MSCs.

\section{Discussion}

Periodontal disease resulting from chronic dental infection can cause periodontal bone loss or, in the worst case, tooth loss. The current investigation evaluated anabolic treatment with a novel stem cell bone-targeting drug, LLP2A-Ale, with or without exogenous MSCs to 

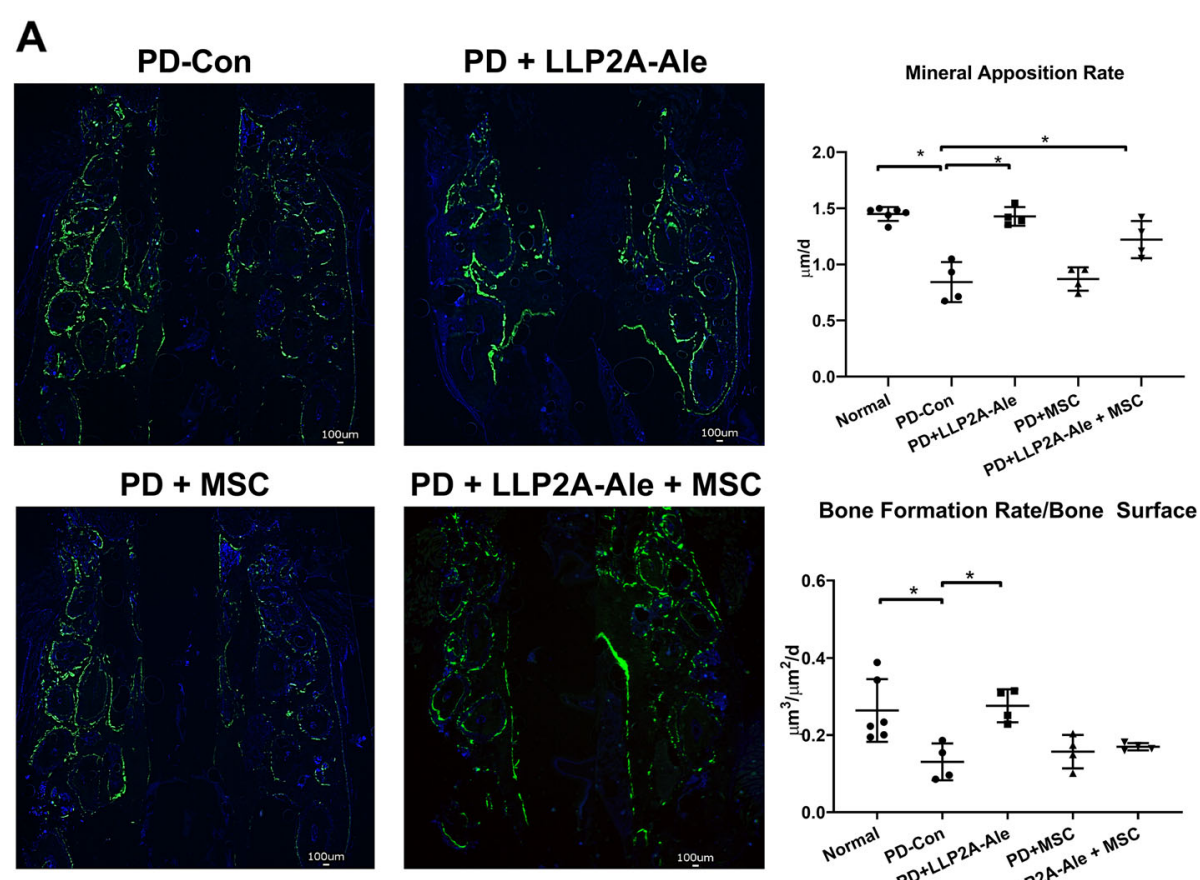

PD + LLP2A-Ale + MSC

\section{Bone Formation Rate/Bone Surface}
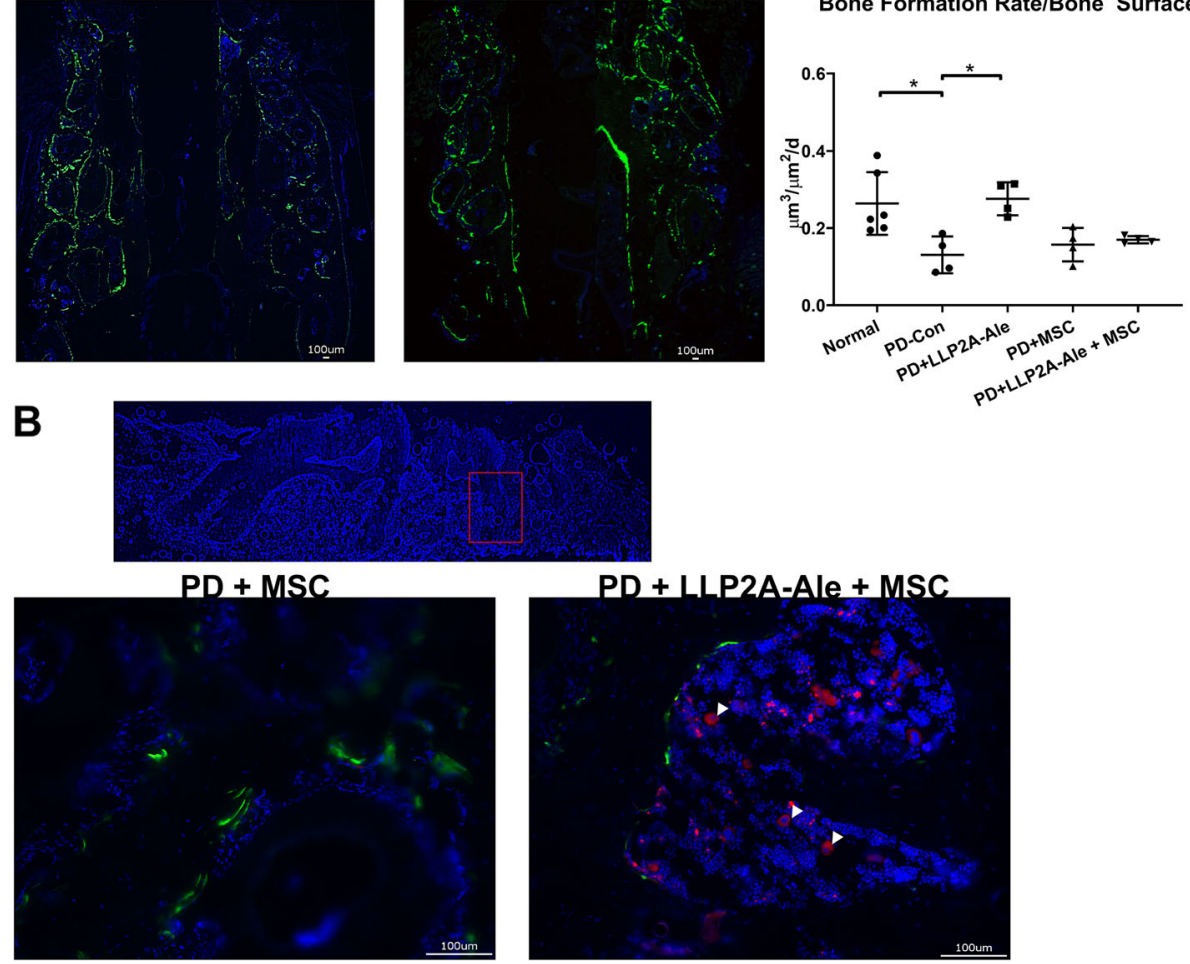

Fig. 3 The PD-induced reduction in maxilla bone formation was reversed by LLP2A-Ale +/- MSCs. a Representative axial maxilla images in each group. All mice received double calcein labeling before euthanization. The right frames are the enlarged areas indicated in the boxes. White arrowheads indicate some transplanted td-Tomato ${ }^{+}$MSCs. b Quantitative measurements of the mineral apposition rate and surface-based bone formation rate at the right maxilla. ${ }^{*} p<0.05$ for comparisons of the indicated groups

promote bone formation and treat alveolar bone loss associated with PD.

Ligature-induced periodontitis is a well-established mouse model that recapitulates the pathogenesis of human periodontal disease, including bacteria film formation, host immune response stimulation, and alveolar bone loss. Ligand-induced bacterial load and peak periodontal bone loss were observed between days $5-8$ postligature, which might sustain for 2-3 weeks, or resulted in tooth loss [13-15]. We started treatment on day 8, representing an intervention protocol. In this study, we provided radiographic and histologic evidence that PD induced alveolar bone loss and suppressed bone formation. Treatment with LLP2A-Ale, alone or in combination with MSCs, rescued alveolar bone loss by augmenting bone formation, supporting the use of an anabolic approach to sustain bone formation for the treatment of bone loss associated with PD. Importantly, PD was also associated with systemic changes in cytokines and chemokines and induced changes in peripheral bone formation and bone mass, resembling a systemic inflammatory disease. LLP2A-Ale monotherapy and LLP2A-Ale + MSCs were equally effective at attenuating the PD-induced suppression of bone formation, sustaining alveolar bone mass, and increasing systemic bone formation. 


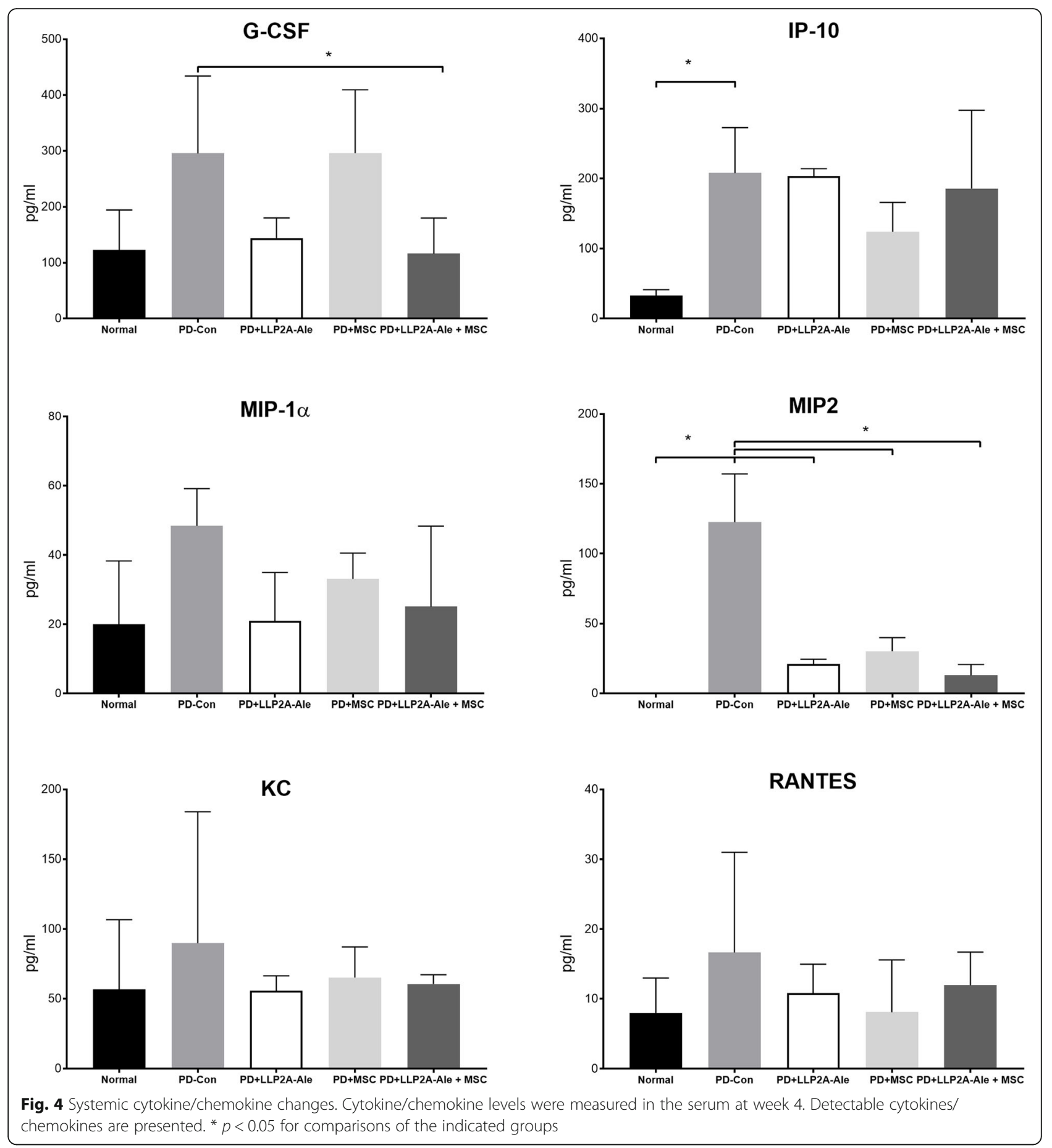

PD is characterized by both inflammation and bone loss [18]. Current medical treatments for PD include flap surgery/root planning, antibacterial oral rinses or antibiotics to control infection, and antiresorptive treatments to control periodontitis. Some non-surgical therapeutics, such as the adjunctive use of probiotics (Clinical study identifier NCT04069611) and Omega-3 polyunsaturated fatty acids (Clinical study identifier NCT04477395) are being evaluated for their efficacies in treating PD. Taurolidine gel was shown to have antimicrobial effects and useful for periodontal therapy [19]. Other experimental drugs, such as chlorhexidine, tetracycline/hydrochloride, locale application of statins, were used as adjunctive treatments to scaling and root planning and were found to have antimicrobial, anti-inflammatory, and modulated bone remodeling process in a rat model of PD [20-23]. 


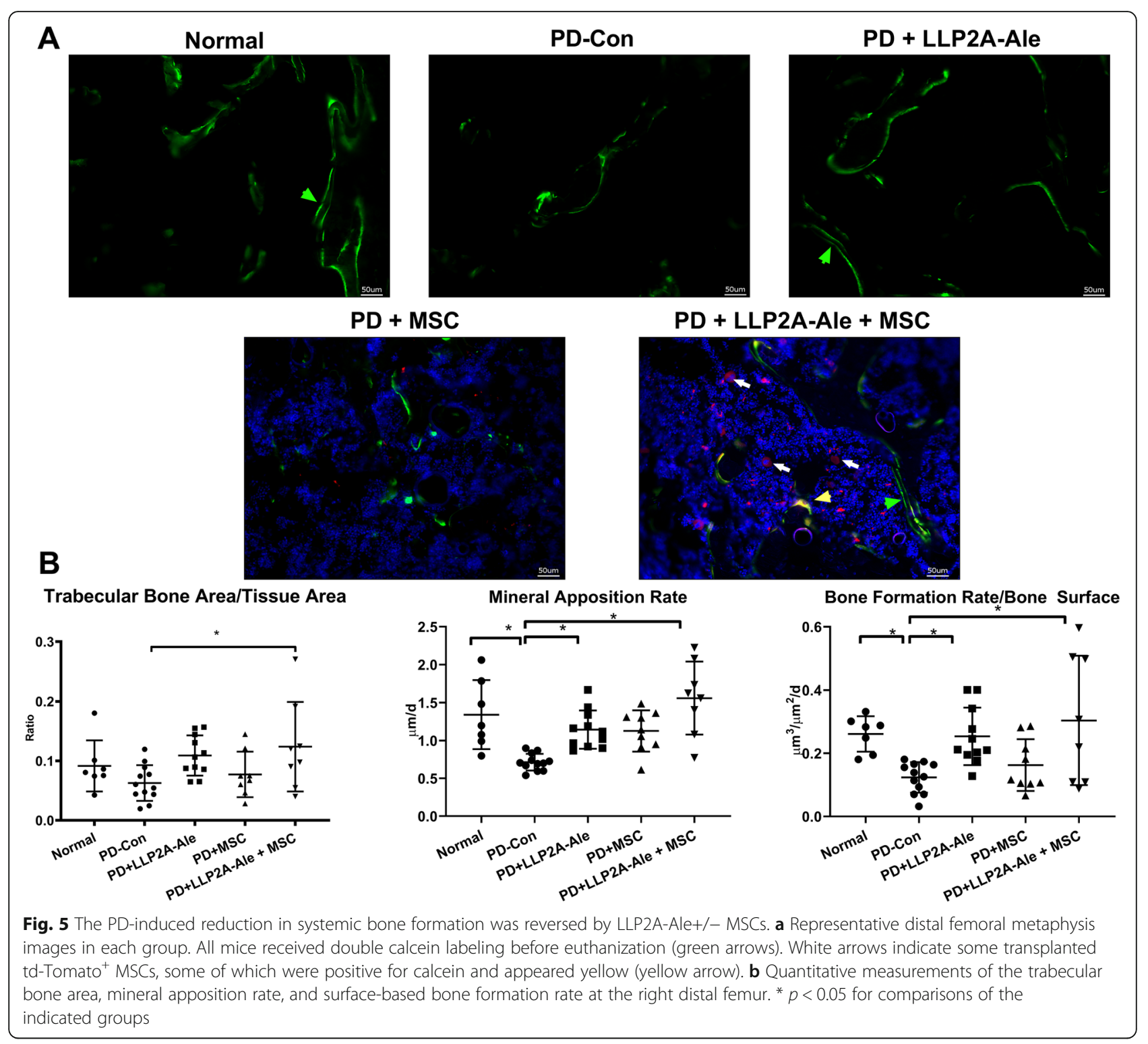

Other medications for osteoporosis, such as bisphosphonates (BPs), are used to treat bone loss resulting from periodontitis. BPs are shown to inhibit alveolar bone resorption [24, 25]. However, chronic or high-dose $\mathrm{BP}$ treatment is associated with a higher risk for the development of osteonecrosis of shown to inhibit alveolar bone resorption [24, 25]. However, chronic or high-dose $\mathrm{BP}$ treatment is associated with a higher risk for the development of osteonecrosis of the jaw in animals [4, 26$28]$ and humans $[3,4,29,30]$. Other medications that affect bone turnover, such as a monoclonal antibody against receptor activator of NF- $\kappa B$ ligand (RANKL), inhibits bone resorption [31]. An antibody against high mobility group box 1 (HMGB1), a nonhistone DNAbinding protein that is secreted into the extracellular matrix in response to inflammation, suppresses the progression of periodontitis through an antiresorptive mechanism [32]. Antiresorptive agents such as BPs are also known for their antiangiogenic actions that potentially are a risk factor for the development of osteonecrosis $[33,34]$. Anabolic treatments, such as teriparatide (human PTH (1-34), which effective against osteoporosis, may also help treat bone loss in both rat and mouse models of PD $[35,36]$. Interestingly, these previous studies reported antiresorptive and anti-inflammatory mechanisms for daily PTH injections instead of the well-known bone growth effects usually observed for PTH $[35,36]$. In one clinical trial, the application of PTH combined with periodontal surgery was superior to periodontal surgery alone at repairing localized bone defects [37]. PTH was shown to enhance alveolar bone formation in conjunction with bone grafts in animal studies [38, 39]. Biweekly 
injections of a new anabolic agent, a monoclonal antibody against sclerostin, for 6 weeks increased periodontal bone formation and alveolar bone in a rat model of PD [40]. Taken together, the data indicate that bone anabolic agents, rather than antiresorptive agents, may be more beneficial for the treatment of periodontal bone loss than anti-resorptive treatment. On the other hand, our previous studies with LLP2A-Ale have found enhanced angiogenesis and blood vessel density in bone $[7,8]$. The ability of LLP2A-Ale to stimulate both angiogenesis and bone formation suggests that this agent has considerable potential as a treatment of periodontal bone loss.

Cytokines have an essential role in the pathogenesis of PD. The host response can attenuate periodontal bone loss, mostly through anti-resorptive mechanisms [41, 42]. In PD tissue, abundant neutrophils are localized in connective tissue $[43,44]$. In the initial steps of periodontal disease, gingival epithelial cells defend against bacterial infection by secreting cytokines such as interleukin (IL)-8, granulocyte-macrophage colony-stimulating factor (GM$\mathrm{CSF}$ ), and monocyte chemotactic protein (MCP-1) from gingival tissues to induce the migration of immune cells into inflammation sites [45-47]. These various inflammatory cytokines, while defend against bacterial infections, may indirectly stimulate osteoclastogenesis and bone resorption. Other chemokines, such as CXCL10, CXCL12, CXCL13, and CCL5, may affect osteoblast precursors or osteoblasts and therefore bone formation [48-52]. When the inflammation is limited to the subepithelial space, it induces damages to the underlying bone through recruitment of osteoclast precursors and induce bone resorption, and may not result in no net bone loss $[53,54]$. If the inflammatory infiltrate persists near the bone, the bone formation will be uncoupled due to the inhibitory effects of cytokines on osteoblasts [18]. However, inflammation is complicated for PD; while low-level inflammation may be protective against the constant bacterial insult, high levels of key inflammatory factors, such as IL- 1 , TNF- $\alpha$, and IL$17 \mathrm{R}$, can result in more severe disease [55-57], and IL-10 may protect against periodontal bone loss [58]. Alendronate was used in LLP2A-Ale to achieve bone-targeted effects $[5,6]$, however, we have not observed anti-resorptive effects in other published studies [5-8]. Additionally, we initiated treatment with LLP2A-Ale with and without MSCs when the periodontal bone loss was established [13, 14], and we chose to focus on evaluating the ability of LLP2A-Ale to augment new bone formation. Three weeks after the ligature was placed to induce PD, the surrounding alveolar bone had reduced the mineral apposition rate, corresponding to reduced osteoblast activity, contributing to the observed alveolar bone loss.

It is among the shortcoming of our report that we did not measure pocket formation, a surrogate for inflammation and bone loss, and the local inflammatory cells infiltration in the periodontal tissues. We measured the systemic serum cytokine levels and found that inflammation assocaited with the PD is not localized to the dental area but was associated with increased systemic levels of interferon-gamma inducible protein 10 (IP-10), macrophage inflammatory protein-1alpha (MIP$1 \alpha)$, RANKL, G-CSF, and macrophage inflammatory protein 2 (MIP2, CXCL2). Higher expression levels of IP-10, RANTE, MCP-1, and MIP2 $\alpha$ were found in gingival biopsies from PD patients $[59,60]$, and a sustained increase in the concentration of both MIP-1a and MCP1 was associated with increasing severity of PD [61]. Moreover, investigators have reported that PD may trigger a systemic immune response associated with chronic disorders, including cardiovascular disease, obesity/type 2 diabetes, and rheumatoid arthritis [62]. In particular, we found that PD increased the circulating levels of G-CSF and MIP2 (CXCL2), both of which attenuated osteoblast differentiation [63-65]; this result was consistent with our observation of a reduced mineral apposition rate locally in the oral region and systemically, which ultimately resulted in localized and generalized bone loss. Both the elevated serum levels of G-CSF and MIP2 levels were suppressed by LLP2A-Ale treatment, thus maintaining periodontal bone formation and bone mass. LLP2A-Ale + MSCs increased systemic bone formation and bone mass, which was consistent with our previous observations in other models of bone disease [5-8]. However, in this PD model of inflammation and bone loss, we did not see an additive effect of MSC transplantation for alveolar bone formation during the treatment of periodontal bone loss despite the observation that transplanted MSCs were homed to the periodontal regions. MSCs are known to have paracrine effects that support anti-inflammatory activity, angiogenesis, and osteogenesis within the bone microenvironment [8], but we have yet to evaluate the fate of these transplanted MSCs engrafted in alveolar bone and ascertain whether they have an anti-inflammatory or pro-angiogenetic effect in the longer term. Rather than using bone-marrow-derived MSCs, other sources of MSCs, especially the oral stem cells that are derived from the periodontal ligament, dental pulp, exfoliated deciduous teeth, dental follicle, and gingival et al., may offer superior regenerative effects to support periodontal repair or regeneration [66-68]. Periodontal ligament -derived stem cells were used to treat PD in humans (clinical trial identifier: NCT02523651). Apart from oral stem cells, other regenerative approaches such as the use of biomaterials, by themselves or used as scaffolds to load cells or drugs, extracellular vesicles, hold promising therapeutic future to repair and grow bone $[69,70]$. Nevertheless, additional studies are needed to determine the beneficial effects of using dental-derived stem cells and LLP2A-Ale for PDinduced bone loss. Perhaps combination treatments of 
dental-derived MSC and an anabolic agent would be ideal to treat more a challenge degenerative dental diseases, such as repairing osteonecrosis of the jaw, to reduce inflammation, restore angiogenesis, and induce bone regeneration.

In conclusion, LLP2A-Ale treatment stimulates alveolar bone formation and reverses alveolar bone loss induced by ligature induced PD. LLP2A-Ale also reduces PD-induced circulating inflammatory proteins, especially, G-CSF and MIP2. Treatment with the combination of MSCs and LLP2A further increases peripheral skeletal bone formation and bone mass but has no additive effect in terms of further increasing alveolar bone formation. Monotherapy with weekly injections of LLP2A-Ale is a novel therapeutic option for the treatment of bone loss associated with periodontitis.

\section{Abbreviations}

PD: Periodontal disease; MSC: Mesenchymal stromal cell; i.p.: Intraperitoneal; i.v.: Intravenous; CXCL2 (MIP2): C-X-C motif chemokine ligand 2; ABC: Alveolar bone crest; CEJ: Cement enamel junction; AC: Alveolar crest; BV/TV: Bone volume to the tissue volume fraction; MAR: Mineral apposition rate; BFR/ BS: Surface-based bone formation rate; DFM: Distal femur metaphysis; RANK L: Receptor activator of NF-KB ligand; HMGB1: High mobility group box 1; IL: Interleukin; GM-CSF: Granulocyte-macrophage colony-stimulating factor; MCP-1: Monocyte chemotactic protein-1

\section{Acknowledgments}

We thank Dr. J Xu and Y Chai from the University of Southern California for their help in choosing and establishing the mouse model of periodontitis for this report.

\section{Authors' contributions}

Research Design: NEL, WY; data acquisition and analysis: MJ, LXL, RWL, WY; interpretation of data:; draft and revise the manuscript: $M J, L X L, R W L, K L, N E L$, WY. All Authors read and approved the manuscript.

\section{Funding}

This report was partially supported by U24DE026914 (J. Lotz overall Pl; W. Yao project PI, to purchase animals and study materials).

\section{Availability of data and materials}

Materials described in the manuscript, including all relevant raw data, were archived in UC Davis share drive, and will be available to any scientist wising to use them for non-commercial purposes by sending a request to the corresponding author.

\section{Ethics approval and consent to participate}

The animal procedures and euthanization protocol were reviewed and approved by the Institutional Animal Care and Use Committee at UC Davis (under protocol \#20977) with institutional guidelines for the Care and Use of laboratory Animals.

\section{Consent for publication}

Not applicable.

\section{Competing interests}

Drs. NE Lane and W. Yao's husbands are the founders of "Bone and Arthritis Regenerative Medicine", who has licensed LLP2A-Ale from the University of California. The other authors do not have a conflict of interest.

\section{Author details}

${ }^{1}$ Department of Internal Medicine, University of California, Davis Medical Center, 4625 2nd Avenue, Sacramento, CA 95817, USA. ²Shanghai Key Laboratory for Prevention and Treatment of Bone and Joint Diseases, Shanghai Institute of Traumatology and Orthopaedics, Ruijin Hospital, Shanghai Jiao Tong University School of Medicine, 197 Ruijin 2nd Road, Shanghai 200025, China. ${ }^{3}$ Yunan Vocational and Technical College of
Agriculture, Kunming 650031, Yunan, China. ${ }^{4}$ Department of Biochemistry \& Molecular Medicine, University of California Davis, Sacramento, CA 95817 USA.

Received: 7 June 2020 Accepted: 27 October 2020

Published online: 13 November 2020

\section{References}

1. Jotwani R, Cutler CW. Adult periodontitis--specific bacterial infection or chronic inflammation? J Med Microbiol. 1998;47(3):187-8.

2. Rodriguez-Lozano FJ, Onate-Sanchez RE. Treatment of osteonecrosis of the jaw related to bisphosphonates and other antiresorptive agents. Med Oral Patol Oral Cir Bucal. 2016;21(5):e595-600.

3. Nicolatou-Galitis O, Razis E, Galiti D, Galitis E, Labropoulos S, Tsimpidakis A, Sgouros J, Karampeazis A, Migliorati C. Periodontal disease preceding osteonecrosis of the jaw (ONJ) in cancer patients receiving antiresorptives alone or combined with targeted therapies: report of 5 cases and literature review. Oral Surg Oral Med Oral Pathol Oral Radiol. 2015;120(6):699-706.

4. Thumbigere-Math V, Michalowicz BS, Hodges JS, Tsai ML, Swenson KK, Rockwell L, Gopalakrishnan R. Periodontal disease as a risk factor for bisphosphonate-related osteonecrosis of the jaw. J Periodontol. 2014;85(2): 226-33.

5. Yao W, Guan M, Jia J, Dai W, Lay YA, Amugongo S, Liu R, Olivos D, Saunders M, Lam KS, et al. Reversing bone loss by directing mesenchymal stem cells to bone. Stem Cells. 2013;31(9):2003-14

6. Guan M, Yao W, Liu R, Lam KS, Nolta J, Jia J, Panganiban B, Meng L, Zhou P, Shahnazari $M$, et al. Directing mesenchymal stem cells to bone to augment bone formation and increase bone mass. Nat Med. 2012;18(3):456-62.

7. Mohan G, Lay EY, Berka H, Ringwood L, Kot A, Chen H, Yao W, Lane NE. A novel hybrid compound LLP2A-ale both prevented and rescued the osteoporotic phenotype in a mouse model of glucocorticoid-induced osteoporosis. Calcif Tissue Int. 2017;100(1):67-79.

8. Yao W, Lay YE, Kot A, Liu R, Zhang H, Chen H, Lam K, Lane NE. Improved mobilization of exogenous mesenchymal stem cells to bone for fracture healing and sex difference. Stem Cells. 2016;34(10):2587-600.

9. Zhang H, Kot A, Lay YE, Fierro FA, Chen H, Lane NE, Yao W. Acceleration of fracture healing by overexpression of basic fibroblast growth factor in the mesenchymal stromal cells. Stem Cells Transl Med. 2017;6(10):1880-93.

10. Abbasi-Kangevari M, Ghamari SH, Safaeinejad F, Bahrami S, Niknejad H. Potential therapeutic features of human amniotic mesenchymal stem cells in multiple sclerosis: immunomodulation, inflammation suppression, angiogenesis promotion, oxidative stress inhibition, neurogenesis induction, MMPs regulation, and Remyelination stimulation. Front Immunol. 2019;10: 238.

11. Pinheiro $\mathrm{CH}$, de Queiroz JC, Guimaraes-Ferreira L, Vitzel KF, Nachbar RT, de Sousa LG, de Souza AL Jr, Nunes MT, Curi R. Local injections of adiposederived mesenchymal stem cells modulate inflammation and increase angiogenesis ameliorating the dystrophic phenotype in dystrophin-deficient skeletal muscle. Stem Cell Rev Rep. 2012;8(2):363-74.

12. Liao W, Zhong J, Yu J, Xie J, Liu Y, Du L, Yang S, Liu P, Xu J, Wang J, et al. Therapeutic benefit of human umbilical cord derived mesenchymal stromal cells in intracerebral hemorrhage rat: implications of anti-inflammation and angiogenesis. Cell Physiol Biochem. 2009;24(3-4):307-16.

13. Abe T, Hajishengallis G. Optimization of the ligature-induced periodontitis model in mice. J Immunol Methods. 2013;394(1-2):49-54.

14. Marchesan J, Girnary MS, Jing L, Miao MZ, Zhang S, Sun L, Morelli T, Schoenfisch MH, Inohara N, Offenbacher S, et al. An experimental murine model to study periodontitis. Nat Protoc. 2018;13(10):2247-67.

15. Zhang T, Wu J, Ungvijanpunya N, Jackson-Weaver O, Gou Y, Feng J, Ho TV, Shen Y, Liu J, Richard S, et al. Smad6 methylation represses NFkappaB activation and periodontal inflammation. J Dent Res. 2018;97(7):810-9.

16. Park CH, Abramson ZR, Taba M Jr, Jin Q, Chang J, Kreider JM, Goldstein SA, Giannobile W. Three-dimensional micro-computed tomographic imaging of alveolar bone in experimental bone loss or repair. J Periodontol. 2007; 78(2):273-81.

17. Kot A, Zhong ZA, Zhang H, Lay YE, Lane NE, Yao W. Sex dimorphic regulation of osteoprogenitor progesterone in bone stromal cells. J Mol Endocrinol. 2017:59(4):351-63.

18. Graves DT, Li J, Cochran DL. Inflammation and uncoupling as mechanisms of periodontal bone loss. J Dent Res. 2011;90(2):143-53. 
19. Pirracchio L, Joos A, Luder N, Sculean A, Eick S. Activity of taurolidine gels on ex vivo periodontal biofilm. Clin Oral Investig. 2018;22(5):2031-7.

20. Prietto NR, Martins TM, Santinoni CDS, Pola NM, Ervolino E, Bielemann AM, Leite FRM. Treatment of experimental periodontitis with chlorhexidine as adjuvant to scaling and root planing. Arch Oral Biol. 2020;110:104600.

21. Fernandes LA, Martins TM, Almeida JM, Nagata MJ, Theodoro LH, Garcia VG, Bosco AF. Experimental periodontal disease treatment by subgingival irrigation with tetracycline hydrochloride in rats. J Appl Oral Sci. 2010;18(6): 635-40

22. Santos BF, Souza EQ, Brigagao MR, Lima DC, Fernandes LA. Local application of statins in the treatment of experimental periodontal disease in rats. J Appl Oral Sci. 2017;25(2):168-76.

23. Bradley AD, Zhang Y, Jia Z, Zhao G, Wang X, Pranke L, Schmid MJ, Wang D, Reinhardt RA. Effect of simvastatin prodrug on experimental periodontitis. J Periodontol. 2016;87(5):577-82.

24. Badran Z, Kraehenmann MA, Guicheux J, Soueidan A. Bisphosphonates in periodontal treatment: a review. Oral Health Prev Dent. 2009;7(1):3-12.

25. Verde ME, Bermejo D, Gruppi A, Grenon M. Effect of bisphosphonates on the levels of Rankl and Opg in gingival crevicular fluid of patients with periodontal disease and post-menopausal osteoporosis. Acta Odontol Latinoam. 2015;28(3):215-21.

26. Aghaloo TL, Kang B, Sung EC, Shoff M, Ronconi M, Gotcher JE, Bezouglaia O, Dry SM, Tetradis S. Periodontal disease and bisphosphonates induce osteonecrosis of the jaws in the rat. J Bone Miner Res. 2011;26(8):1871-82.

27. Aghaloo TL, Cheong S, Bezouglaia O, Kostenuik P, Atti E, Dry SM, Pirih FQ, Tetradis S. RANKL inhibitors induce osteonecrosis of the jaw in mice with periapical disease. J Bone Miner Res. 2014:29(4):843-54.

28. Kim T, Kim S, Song M, Lee C, Yagita H, Williams DW, Sung EC, Hong C, Shin $\mathrm{KH}$, Kang MK, et al. Removal of pre-existing periodontal inflammatory condition before tooth extraction ameliorates medication-related osteonecrosis of the jaw-like lesion in mice. Am J Pathol. 2018;188(10):231827.

29. Kos M. Association of dental and periodontal status with bisphosphonaterelated osteonecrosis of the jaws. A retrospective case controlled study. Arch Med Sci. 2014;10(1):117-23.

30. Ruggiero SL, Dodson TB, Fantasia J, Goodday R, Aghaloo T, Mehrotra B, O'Ryan F, American Association of O, Maxillofacial S. American Association of Oral and Maxillofacial Surgeons position paper on medication-related osteonecrosis of the jaw--2014 update. J Oral Maxillofac Surg. 2014;72(10): $1938-56$.

31. Lin X, Han X, Kawai T, Taubman MA. Antibody to receptor activator of NFkappaB ligand ameliorates T cell-mediated periodontal bone resorption. Infect Immun. 2011;79(2):911-7.

32. Vogel S, Borger V, Peters C, Forster M, Liebfried P, Metzger K, Meisel R, Daubener W, Trapp T, Fischer JC, et al. Necrotic cell-derived high mobility group box 1 attracts antigen-presenting cells but inhibits hepatocyte growth factor-mediated tropism of mesenchymal stem cells for apoptotic cell death. Cell Death Differ. 2015;22(7):1219-30.

33. Ishtiaq S, Edwards S, Sankaralingam A, Evans BA, Elford C, Frost ML, Fogelman I, Hampson G. The effect of nitrogen containing bisphosphonates, zoledronate and alendronate, on the production of proangiogenic factors by osteoblastic cells. Cytokine. 2015;71(2):154-60.

34. Or C, Cui J, Matsubara J, Forooghian F. Pro-inflammatory and antiangiogenic effects of bisphosphonates on human cultured retinal pigment epithelial cells. Br J Ophthalmol. 2013;97(8):1074-8.

35. Barros SP, Silva MA, Somerman MJ, Nociti FH Jr. Parathyroid hormone protects against periodontitis-associated bone loss. J Dent Res. 2003;82(10): 791-5.

36. Otawa M, Tanoue R, Kido H, Sawa Y, Yamashita J. Intermittent administration of parathyroid hormone ameliorates periapical lesions in mice. J Endod. 2015;41(5):646-51.

37. Bashutski JD, Eber RM, Kinney JS, Benavides E, Maitra S, Braun TM, Giannobile W, McCauley LK. Teriparatide and osseous regeneration in the oral cavity. N Engl J Med. 2010;363(25):2396-405.

38. Jung RE, Cochran DL, Domken O, Seibl R, Jones AA, Buser D, Hammerle CH. The effect of matrix bound parathyroid hormone on bone regeneration. Clin Oral Implants Res. 2007;18(3):319-25.

39. Valderrama P, Jung RE, Thoma DS, Jones AA, Cochran DL. Evaluation of parathyroid hormone bound to a synthetic matrix for guided bone regeneration around dental implants: a histomorphometric study in dogs. J Periodontol. 2010;81(5):737-47.
40. Taut AD, Jin Q, Chung JH, Galindo-Moreno P, Yi ES, Sugai JV, Ke HZ, Liu M, Giannobile W. Sclerostin antibody stimulates bone regeneration after experimental periodontitis. J Bone Miner Res. 2013;28(11):2347-56.

41. Thomas MV, Puleo DA. Infection, inflammation, and bone regeneration: a paradoxical relationship. J Dent Res. 2011;90(9):1052-61.

42. Graves D. Cytokines that promote periodontal tissue destruction. J Periodontol. 2008;79(8 Suppl):1585-91.

43. Queiroz-Junior CM, Pacheco CM, Fonseca AH, Klein A, Caliari MV, de Francischi JN. Myeloperoxidase content is a marker of systemic inflammation in a chronic condition: the example given by the periodontal disease in rats. Mediat Inflamm. 2009;2009:760837.

44. Gomes DA, Pires JR, Zuza EP, Muscara MN, Herrera BS, Spolidorio LC, Toledo $\mathrm{BE}$, Spolidorio DM. Myeloperoxidase as inflammatory marker of periodontal disease: experimental study in rats. Immunol Investig. 2009;38(2):117-22.

45. Koss MA, Castro CE, Carino S, Lopez ME. Histopathologic and histomorphometric studies and determination of IL-8 in patients with periodontal disease. J Indian Soc Periodontol. 2014;18(2):145-9.

46. Lagdive SS, Marawar PP, Byakod G, Lagdive SB. Evaluation and comparison of interleukin-8 (IL-8) level in gingival crevicular fluid in health and severity of periodontal disease: a clinico-biochemical study. Indian J Dent Res. 2013; 24(2):188-92.

47. Youn BS, Jang IK, Broxmeyer HE, Cooper S, Jenkins NA, Gilbert DJ, Copeland NG, Elick TA, Fraser MJ Jr, Kwon BS. A novel chemokine, macrophage inflammatory protein-related protein-2, inhibits colony formation of bone marrow myeloid progenitors. J Immunol. 1995;155(5):2661-7.

48. Wegman F, Poldervaart MT, van der Helm YJ, Oner FC, Dhert WJ, Alblas J. Combination of bone morphogenetic protein-2 plasmid DNA with chemokine CXCL12 creates an additive effect on bone formation onset and volume. Eur Cell Mater. 2015;30:1-10 discussion 10-11.

49. Kim GW, Han MS, Park HR, Lee EJ, Jung YK, Usmani SE, Ulici V, Han SW, Beier F. CXC chemokine ligand 12a enhances chondrocyte proliferation and maturation during endochondral bone formation. Osteoarthr Cartil. 2015; 23(6):966-74.

50. Wintges K, Beil FT, Albers J, Jeschke A, Schweizer M, Claass B, Tiegs G, Amling $\mathrm{M}$, Schinke T. Impaired bone formation and increased osteoclastogenesis in mice lacking chemokine (C-C motif) ligand 5 (Ccl5). J Bone Miner Res. 2013;28(10):2070-80.

51. Wise JK, Sumner DR, Virdi AS. Modulation of stromal cell-derived factor-1/ CXC chemokine receptor 4 axis enhances rhBMP-2-induced ectopic bone formation. Tissue Eng Part A. 2012;18(7-8):860-9.

52. Wei L, Kanbe K, Lee M, Wei X, Pei M, Sun X, Terek R, Chen Q. Stimulation of chondrocyte hypertrophy by chemokine stromal cell-derived factor 1 in the chondro-osseous junction during endochondral bone formation. Dev Biol. 2010;341(1):236-45.

53. Lemaire V, Tobin FL, Greller LD, Cho CR, Suva L. Modeling the interactions between osteoblast and osteoclast activities in bone remodeling. J Theor Biol. 2004:229(3):293-309.

54. Beaupre GS, Orr TE, Carter DR. An approach for time-dependent bone modeling and remodeling--theoretical development. J Orthop Res. 1990; 8(5):651-61.

55. Pretzl B, El Sayed N, Cosgarea R, Kaltschmitt J, Kim TS, Eickholz P, Nickles K, Baumer A. IL-1-polymorphism and severity of periodontal disease. Acta Odontol Scand. 2012;70(1):1-6.

56. Zhu L, Wu Y, Wei H, Xing X, Zhan N, Xiong H, Peng B. IL-17R activation of human periodontal ligament fibroblasts induces IL-23 p19 production: differential involvement of NF-kappaB versus JNK/AP-1 pathways. Mol Immunol. 2011;48(4):647-56.

57. Mori G, Brunetti G, Colucci S, Oranger A, Ciccolella F, Sardone F, Pignataro P, Mori C, Karapanou V, Ballini A, et al. Osteoblast apoptosis in periodontal disease: role of TNF-related apoptosis-inducing ligand. Int J Immunopathol Pharmacol. 2009;22(1):95-103.

58. Zhang Q, Chen B, Yan F, Guo J, Zhu X, Ma S, Yang W. Interleukin-10 inhibits bone resorption: a potential therapeutic strategy in periodontitis and other bone loss diseases. Biomed Res Int. 2014;2014:284836.

59. Lappin DF, McGregor AM, Kinane DF. The systemic immune response is more prominent than the mucosal immune response in the pathogenesis of periodontal disease. J Clin Periodontol. 2003;30(9):778-86.

60. Gemmell E, Carter CL, Seymour GJ. Chemokines in human periodontal disease tissues. Clin Exp Immunol. 2001;125(1):134-41.

61. Nisha KJ, Suresh A, Anilkumar A, Padmanabhan S. MIP-1alpha and MCP-1 as salivary biomarkers in periodontal disease. Saudi Dent J. 2018;30(4):292-8. 
62. Fernandez-Solari J, Barrionuevo P, Mastronardi CA. Periodontal disease and its systemic associated diseases. Mediat Inflamm. 2015;2015: 153074.

63. Zhang Z, Yuan W, Deng J, Wang D, Zhang T, Peng L, Tian H, Wang Z, Ma J. Granulocyte colony stimulating factor (G-CSF) regulates neutrophils infiltration and periodontal tissue destruction in an experimental periodontitis. Mol Immunol. 2020;117:110-21.

64. Greer A, Irie K, Hashim A, Leroux BG, Chang AM, Curtis MA, Darveau RP. Site-specific neutrophil migration and CXCL2 expression in periodontal tissue. J Dent Res. 2016;95(8):946-52.

65. Kuwabara H, Wada T, Oda T, Yoshikawa H, Sawada N, Kokai Y, Ishii S. Overexpression of the granulocyte colony-stimulating factor gene impairs bone morphogenetic protein responsiveness in mice. Lab Investig. 2001; 81(8):1133-41.

66. Wei W, An Y, An Y, Fei D, Wang Q. Activation of autophagy in periodontal ligament mesenchymal stem cells promotes angiogenesis in periodontitis. J Periodontol. 2018;89(6):718-27.

67. Trubiani O, Pizzicannella J, Caputi S, Marchisio M, Mazzon E, Paganelli R, Paganelli A, Diomede F. Periodontal ligament stem cells: current knowledge and future perspectives. Stem Cells Dev. 2019;28(15):995-1003.

68. Diomede F, D'Aurora M, Gugliandolo A, Merciaro I, Ettorre V, Bramanti A, Piattelli A, Gatta V, Mazzon E, Fontana A, et al. A novel role in skeletal segment regeneration of extracellular vesicles released from periodontalligament stem cells. Int J Nanomedicine. 2018;13:3805-25.

69. Trubiani O, Marconi GD, Pierdomenico SD, Piattelli A, Diomede F, Pizzicannella J. Human oral stem cells, biomaterials and extracellular vesicles: a promising tool in bone tissue repair. Int J Mol Sci. 2019;20(20):4987.

70. Chaparro Padilla A, Weber Aracena L, Realini Fuentes O, Albers Busquetts D, Hernandez Rios M, Ramirez Lobos V, Pascual La Rocca A, Nart Molina J, Beltran Varas V, Acuna-Gallardo S, et al. Molecular signatures of extracellular vesicles in oral fluids of periodontitis patients. Oral Dis. 2020. https://doi.org/ 10.1111/odi.13338.

\section{Publisher's Note}

Springer Nature remains neutral with regard to jurisdictional claims in published maps and institutional affiliations.

Ready to submit your research? Choose BMC and benefit from:

- fast, convenient online submission

- thorough peer review by experienced researchers in your field

- rapid publication on acceptance

- support for research data, including large and complex data types

- gold Open Access which fosters wider collaboration and increased citations

- maximum visibility for your research: over $100 \mathrm{M}$ website views per year

At $\mathrm{BMC}$, research is always in progress.

Learn more biomedcentral.com/submissions 